\title{
Habilidade de Comunicação Intencional de Bebês: O Que Pensam as Mães?
}

\author{
Laísy de Lima Nunes ${ }^{1}$ \\ Fabíola de Sousa Braz Aquino \\ Universidade Federal da Paraíba
}

\begin{abstract}
RESUMO - Este estudo investigou as percepções maternas acerca da habilidade comunicativa intencional infantil. Pesquisas destacam o impacto dessas percepções nas interações estabelecidas entre mãe e bebê e suas repercussões no desenvolvimento da linguagem e da cognição social infantil. Participaram do estudo 40 mães de bebês de 4 e 9 meses. Os resultados mostram variações nas percepções maternas quanto às habilidades de comunicação intencional dos bebês. Os relatos maternos sobre os bebês de 9 meses evidenciam o uso de recursos comunicativos intencionais expressos por vocalizações, alternância do olhar, e gesto de apontar. Discutem-se as implicações dessas percepções nas interações adulto-bebê, no desenvolvimento sociocomunicativo infantil e em contextos de desenvolvimento e educação infantil.
\end{abstract}

Palavras-chave: percepções maternas, intencionalidade comunicativa, bebês, desenvolvimento inicial

\section{Babies' Intentional Communication Ability: What the Mothers Think?}

\begin{abstract}
This study investigated maternal perceptions of infant intentional communicative ability. Researchs highlight the impact of these perceptions on the interactions established between mother and baby and their repercussions on language development and infant social cognition. The study included 40 mothers of babies aged 4 and 9 months. The results show variations in maternal perceptions about infants' intentional communicative abilities. Maternal reports about babies 9 months demonstrate the use of intentional communicative resources expressed by vocalizations, gaze alternation and pointing gesture. We discuss the implications of these perceptions in adult-child interactions, in child sociocomunicativo development and in contexts of child development and education.
\end{abstract}

Keywords: maternal perceptions, communicative intentionality, babies, early development

A habilidade de comunicação intencional é um tipo especial de intencionalidade que emerge no comportamento infantil e um dos elementos cruciais para a gênese da comunicação, que cria formas peculiares de aprendizagem cultural e engajamento (Braz Aquino \& Salomão, 2010, 2011b; Sanchez, 1991; Tomasello, 1999, 2003). Sobre esse tema, Grosse, Behne, Carpenter e Tomasello (2010), Tomasello (2003) e Tomasello e Carpenter (2007) defendem que ocorre, no final do primeiro ano de vida, o que eles denominaram de revolução dos nove meses, entendida como um fenômeno marcado pelo início do engajamento do bebê em relações triádicas e em episódios de atenção conjunta. Tais episódios envolvem o bebê, o adulto e um objeto ou evento, com o qual ambos compartilham o interesse. Para esses autores, a partir desse período, os bebês são capazes de acompanhar o olhar do adulto direcionado para um objeto, evento ou pessoa, demonstrando interesse no que o adulto observa, usar o adulto como referência social e aprender de forma imitativa.

Para esses autores, a partir dos 9 meses de vida, determinadas capacidades cognitivas e comunicativas dos bebês tornam-se intencionais. Entre essas capacidades, Tomasello e Carpenter (2007) destacam as seguintes: a capacidade de manipulação social e comunicação cooperativa, por meio da qual antes mesmo da aquisição da linguagem os bebês já se comunicam por gestos, como o apontar; a atividade colaborativa, que se refere à capacidade

1 Endereço para correspondência: Rua Mário Batista Junior, n. 75, Ed. Quinta Avenida, apto. 301, Miramar, João Pessoa, PB, Brasil, CEP: 58043130.E-mail: fabiolabrazaquino@gmail.com das crianças de desenvolver atividades em grupos com objetivos compartilhados e apresentar formas de colaboração entre si; e as aprendizagens social e instrumental, referentes ao fato das crianças, em torno de um ano, frequentemente, já responderem a instruções e imitarem propositalmente as ações dos outros.

Tomasello $(1999,2003)$ esclarece que a habilidade de comunicação intencional infantil é a principal causa e consequência da revolução dos nove meses e que formas emergentes de intencionalidade do bebê em suas próprias ações sensório-motoras proporcionam a compreensão dos outros como agentes intencionais. D’Entremont e Seamans (2007) ratificam que a comunicação intencional só é entendida pelo bebê quando ele já tem uma concepção de si mesmo e dos outros como agentes intencionais. A existência de uma interação, ou seja, a presença do outro que interatue e signifique as ações do bebê é imprescindível à compreensão dos atos intencionais.

$\mathrm{Na}$ esteira dessas considerações, Rivero (2003, 2010) apresenta uma proposta teórico-conceitual, segundo a qual os principais indicadores de intencionalidade são: a coerência dos atos comunicativos, por meio dos quais a criança coordena diversos comportamentos direcionados a pessoas e/ou objetos; a orientação da conduta para um parceiro social; a direção para uma meta; o referente; e o efeito sobre o parceiro. Nesse sentido, a autora reafirma a natureza social dos processos comunicativos e defende que a intencionalidade comunicativa, além de abranger estados mentais dos bebês, é um processo observável que progressivamente emerge $\mathrm{e}$ se constitui nos cenários interativos. 
Em outra perspectiva, Striano, Rochat e colaboradores (Rochat, 2007, 2009; Striano \& Reid, 2006; Striano \& Rochat, 1999) ilustram que, desde o segundo mês, os bebês têm diversas habilidades comunicativas, sendo capazes, por exemplo, de usar movimentos para sinalizar um objeto desejado, tais como movimentar o corpo, levantar braços ou mãos. Segundo afirmam, nesse período ocorre o que designam revolução dos dois meses, na qual novas habilidades sociais se desenvolvem e aparecem os primeiros sinais de comportamentos intencionais. Tais comportamentos aprimoram-se, gradativamente, ao longo dos meses seguintes, até que por volta dos 9 meses apresentam formas mais elaboradas. Essas novas configurações comportamentais permitem que, ao apontar para objetos ou eventos, o bebê tente chamar a atenção do outro e tenha seu comportamento modificado de acordo com os sinais sociais que recebe.

Legerstee (2013), Legerstee e Markova (2007), Markova e Legerstee (2008), com base em fundamentos neurocognitivos e sociointerativos, argumentam que a consciência que o bebê tem do outro com o qual interage permite formas aprimoradas de relações diádicas, que, juntamente com outros pré-requisitos biológicos e com aspectos sociais, são fundamentais ao desenvolvimento da intencionalidade comunicativa, à estruturação de situações triádicas e às representações compartilhadas. De acordo com Gallese e Rochat (2013) e Legerstee (2013), tais representações são simultaneamente ativadas no cérebro de dois agentes, e possibilitam que os bebês entendam não apenas $o$ quê os outros fazem, mas porquê o fazem. Estes autores defendem que essa habilidade sociocognitiva revela uma consciência do bebê sobre os estados intencionais dos outros e que variações nas experiências sociais podem produzir variações na intersubjetividade, nos laços afetivos e subsequentemente nos estados mentais de consciência.

É importante lembrar que anteriormente, Vygotsky (1932/1996) já havia apresentado os elementos e as características típicas da formação do comportamento social do bebê no primeiro ano de vida. Ele defendeu que mesmo antes do domínio da linguagem, há uma sociabilidade específica do bebê, devido a sua situação peculiar de desenvolvimento e à mediação social. Em consonância com a ideia de processo de aquisição da linguagem, Vygotsky (1996, 1984/2007) considerou a existência da inteligência prática instrumental no período pré-verbal do desenvolvimento infantil e discorreu sobre os elementos pré-linguísticos, como o choro, o olhar, o sorriso e o gesto de apontar, por exemplo, enquanto ações essencialmente comunicativas. Para ele, no início da vida, os bebês começam a demonstrar habilidades comunicativas e cognitivas, que progressivamente vão adquirindo um caráter mais complexo e possibilitando novas formas de comportamentos expressivos dos desejos infantis (Vygotsky, 1996).

No tocante a esse processo de desenvolvimento das habilidades infantis, Vygotsky e Luria (1996) utilizam o conceito de reequipamento, segundo o qual o bebê não apenas cresce e amadurece, mas adquire novas habilidades, formas de comportamento mais elaboradas. Segundo afirmam, a partir do nono mês, o bebê torna-se capaz de empregar ferramentas de modo simples, tal como usar um objeto para alcançar outro, o que sugere que, antes mesmo que se forme a linguagem, ele já apresenta comportamentos orientados para um fim. Vygotsky (1996) defende que aos 10 meses de vida, ocorre uma importante virada no desenvolvimento, na qual se desenvolvem nos bebês formas de comportamento mais complexas, como o emprego de palavras para expressar uma vontade, por exemplo. Esse período, de acordo com o modelo histórico-cultural, é um dos marcos da crise do primeiro ano de vida.

Nesta direção, apesar de algumas divergências, a maioria dos teóricos parece está perto de um consenso de que os atos comunicativos intencionais surgem antes das primeiras palavras, mais precisamente no último trimestre do primeiro ano, entre 9 e 12 meses (Bloom, 2000). Essa idade representa um período crítico para a emergência da comunicação intencional, que ocorre ao longo de transições cognitivas, de mudanças nas habilidades manipulativas e de mobilidade, e da capacidade de compartilhar emoções e experiências (Olson, Astington, \& Zelazo, 1999).

Striano e Reid (2006) destacam a importância da relação entre comunicação intencional (com o surgimento gradativo de gestos de caráter sociocomunicativo e simbólico), contextos de atenção conjunta, e aquisição da linguagem. A habilidade de comunicação intencional, assim como a compreensão dos outros como agentes intencionais, está intimamente relacionada às habilidades sociocognitivas triádicas, evidenciadas em contextos de atenção conjunta, a qual representa um evento decisivo na maneira como as crianças se relacionam com o mundo.

Desta forma, a relação do bebê com outras pessoas e a intersubjetividade possibilitam seu desenvolvimento e relação com o mundo (Gratier \& Trevarthen, 2007; Nogueira \& Seidl-de-Moura, 2007; Reznick, 1999; Trevarthen, 1979, 2011). Laakso, Poikkeus, Katajamäki e Lyytinen (1999) corroboram o pressuposto de que o período em torno do primeiro ano de vida é crítico para o desenvolvimento de intenções comunicativas e sinais convencionais. Também segundo esses autores, é importante considerar as percepções e o estilo parental sensível e responsivo para o desenvolvimento da comunicação intencional.

De acordo com vários estudos na área do desenvolvimento (Feldman \& Reznick, 1996; Harkness \& Super, 1996, 2006; Seidl-de-Moura, et al., 2013), são as percepções parentais sobre o desenvolvimento infantil que fundamentam o comportamento dos pais, mesmo que de forma implícita, tendo em vista que as ações parentais não são respostas acidentais aos comportamentos da criança. Isto porque os pais têm noções ou ideias do modo como devem tratar seus filhos e dos princípios que norteiam suas ações. Dessa forma, a maneira como os pais percebem o desenvolvimento infantil influencia as práticas com o bebê e, consequentemente, tem impacto no desenvolvimento deste.

Feldman e Reznick (1996) defenderam a existência e importância de um tipo específico de percepção parental, a saber, a percepção parental acerca da habilidade de comunicação intencional dos bebês. Essa percepção, em particular, é considerada relevante porque demonstra, explícita ou implicitamente, como a compreensão acerca da habilidade mental infantil dita as estratégias e media a habilidade parental para detectar e responder aos estados e às intenções dos bebês. As mães diferem muito entre si 
sobre essas percepções, pois, enquanto algumas atribuem intencionalidade aos atos infantis com bastante frequência, outras hesitam em fazê-lo e, por vezes, deixam alguns comportamentos passarem despercebidos. Essas diferenças nas formas de percepções maternas podem ter efeitos importantes no comportamento da criança, ao longo do desenvolvimento. Assim, mães que atribuem intenção aos comportamentos negativos do bebê podem puni-los por considerar que eles se comportam mal de propósito (Burchinal, Skinner, \& Reznick, 2010; Reznick \& Schwartz, 2001).

Considerando que as interações diádicas fomentam um contexto para o desenvolvimento do potencial humano para comportamentos intencionais, estudar as percepções maternas é essencial para conhecer as bases que fundamentam as estratégias usadas pelas mães para responder aos comportamentos dos filhos (Bornstein, 2013; Feldman \& Reznick, 1996; Legerstee \& Markova, 2007; Mendes \& Seidl-de-Moura, 2009). Diante disso, outro aspecto importante nos contextos interativos é a adequação das práticas maternas à idade do bebê e às suas competências, ou seja, a forma como a mãe interage com a criança deve ser compatível com a habilidade de compreensão do bebê, cabendo à mãe se ajustar às capacidades infantis e aos bebês responderem às interações com ela, num movimento bidirecional. Todavia, isso só é possível se a percepção materna acerca da habilidade de comunicação intencional infantil for condizente com as habilidades reais e potenciais do bebê (Rivero, 2010).

A partir do exposto deriva-se a importância das interações sociais e das percepções maternas para o desenvolvimento sociocomunicativo e linguístico infantil. Isto porque, a habilidade de comunicação intencional do bebê não se refere a uma habilidade infantil isolada, mas ocorre no contexto amplo da interação, no qual os adultos atribuem significados aos comportamentos das crianças e, portanto, nos intercâmbios estabelecidos, tais atribuições contribuem para o desenvolvimento infantil. Ademais, se as mães compreendem a importância dessas habilidades iniciais e mostram-se atentas aos comportamentos dos bebês, elas podem criar situações que potencializem o desenvolvimento infantil, estimulando o bebê e contribuindo para que ele possa exercer um papel de parceiro ativo nas interações estabelecidas.

Diante da relevância dessa temática, o presente estudo buscou investigar as percepções maternas acerca da habilidade de comunicação intencional dos bebês no primeiro ano de vida. Especificamente, buscou-se identificar as possíveis variações dessas percepções, considerando os períodos de desenvolvimento infantil, e discutir o impacto delas nas interações mãe-bebê.

\section{Método}

\section{Participantes}

Participaram desse estudo 40 mães, sendo 20 mães de bebês de 4 meses e 20 mães de bebês de 9 meses. A idade das mães participantes variou entre 21 e 36 anos, com média 29,23 (DP = 4,54). Todas as mães eram casadas ou estavam em uma relação estável, residiam em seus próprios domicílios, possuíam nível instrucional a partir do ensino médio completo e ocupações diversas.

\section{Instrumentos e procedimento}

A pesquisa foi submetida ao Comitê de Ética do Centro de Ciências da Saúde da Universidade Federal da Paraíba (UFPB), obtendo aprovação através do protocolo de número 0331/12. CAAE: 04762412.2.0000.5188. A participação das mães no estudo esteve condicionada à assinatura do Termo de Consentimento Livre e Esclarecido.

Foi utilizado um questionário sociodemográfico e uma entrevista semiestruturada resultante do processo de adaptação semântica do Infant Intentionality Questionnaire IIQ (Feldman \& Reznick, 1996), questionário que tem como principal foco a apreensão das percepções maternas acerca da comunicação intencional de bebês. Em sua forma original, o IIQ é um instrumento composto por 41 questões e dividido em quatro seções. No entanto, por ser um questionário em inglês, o IIQ passou por um processo de tradução e adaptação semântica antes de ser utilizado. Por apresentar uma escala de cinco pontos, variando entre dois extremos (ex.: um pouco/ muito; não é possível/definitivamente), considerou-se que esse tipo de estrutura reduzia as possibilidades de resposta das mães e limitava uma compreensão mais aprofundada sobre suas percepções acerca da comunicação intencional infantil. Diante disto, optou-se por dar ao instrumento um formato de entrevista semiestruturada.

Com vistas a atender as etapas de adaptação do instrumento, foi realizado um estudo piloto para verificar a compreensão das participantes sobre o conteúdo e a adequabilidade da entrevista aos objetivos do estudo. A partir dos dados coletados nessa etapa, foi verificado que duas das 41 perguntas não foram bem compreendidas pelas mães, por apresentarem termos ou expressões pouco claras que levantaram questionamentos das participantes.

O instrumento também foi submetido a uma análise de juízes peritos na área de desenvolvimento infantil. Essa técnica é apresentada por Pasquali (2010) como útil na construção de instrumentos e consiste na verificação da adequabilidade das questões ao construto estudado e aos objetivos propostos, cabendo aos juízes peritos avaliarem se as questões que compõem a entrevista estão se referindo de forma adequada ao que pretendem averiguar. Com relação às considerações dos peritos na área, três questões foram consideradas inadequadas. Ademais, termos utilizados originalmente por Feldman e Reznick (1996), tais como "consciência", também foram alvo de questionamentos entre os juízes. Desse modo, na coleta de dados, foi utilizada uma versão adaptada do IIQ em formato de entrevista, na qual foram feitas alterações em seis perguntas, a fim de empregar termos que priorizaram a compreensão materna sobre os itens.

Após a realização da coleta de dados, foram levantadas as frequências referentes aos dados do questionário sociodemográfico e as entrevistas foram transcritas de forma 
literal. A partir disso, foi realizada a leitura flutuante e o levantamento das frequências de respostas mais prevalentes referidas pelas mães em cada grupo de idade estudado. Além da frequência, foram consideradas as semelhanças e contradições dos discursos das mães, sendo feita uma análise qualitativa de conteúdo (Bardin, 1977/2002; Franco, 2008), com foco nos aspectos referentes às percepções maternas acerca da habilidade de comunicação intencional de seus bebês.

No presente artigo serão apresentados os resultados de 21 questões, que correspondem aos itens de duas seções do instrumento, a saber: Autoeficácia dos bebês (percepção materna sobre a capacidade dos bebês para fazerem algo com o objetivo de comunicar e satisfazer suas próprias necessidades) e Eficácia dos bebês nos outros (percepção materna sobre a capacidade dos bebês de comunicar suas necessidades e de agir sobre outros intencionalmente).

\section{Resultados}

Inicialmente, buscou-se conhecer a Percepção materna acerca da autoeficácia dos bebês. Para tanto foi perguntado: "Quando seu bebê chora, você sente que ele quer lhe dizer que está com dor ou triste?”. Em relação a essa pergunta, 16 mães do grupo de bebês de quatro meses responderam que seus filhos comunicam dor ou tristeza quando choram. Duas mães responderam que o choro dos seus bebês não significa necessariamente que eles estão com dor ou tristes, mas pode ter vários outros significados ("Eu acho que, quando ele chora, ele quer dizer alguma coisa, não necessariamente que tá triste ou com dor. Assim, ou ele quer uma atenção, ou tá feito xixi, cocô, assim, tem alguma coisa que tá incomodando." - M14). Já entre as mães de bebês de nove meses, 11 afirmaram que sentem que, quando seus bebês choram, eles querem dizer que estão com dor ou tristes: "Sim, com dor, principalmente." (M18). Sete entre essas 20 mães alegaram que o choro pode significar dor ou tristeza, mas que, geralmente, ele indica muito mais do que isso.

Em relação à pergunta "Quando seu bebê chora, você acha que ele sabe que deve fazer algo para satisfazer a necessidade dele?", 12 mães de bebês de quatro meses responderam afirmativamente, explicando que o choro representa uma forma que o bebê tem de fazer algo para ter suas necessidades satisfeitas. "Eu creio que sim, porque ele não ia chorar à toa. Se ele tá chorando, é porque ele acha que vai servir de alguma coisa. É a forma que ele tem, já que não sabe falar ainda" (M8). Entre as mães de bebês de nove meses, 15 afirmaram perceber que, quando seus bebês choram, eles sabem que devem fazer algo para satisfazer suas necessidades, como no exemplo: "Eu acho que o choro é esse algo. Eu acho que ele transmite isso com o choro." (M9).

No que se refere à questão "Quando seu bebê está sujo, com fome ou cansado, você acha que ele sente que pode fazer algo sobre isso?". A partir dos relatos maternos, verificou-se que, das 20 mães de bebês de quatro meses, 14 mães responderam afirmativamente à essa questão, sendo que quando explicitaram de que forma o bebê expressa seus estados, dez alegaram que o choro é o principal meio que o bebê dispõe para comunicar que está sujo, com fome ou cansado. Ainda nesse grupo, uma mãe relatou que, quando sua filha está suja, ela faz movimentos repetitivos com os pés.

Entre as mães de bebês de nove meses, 11 afirmaram que percebem seus bebês como sendo capazes de fazer algo sobre suas necessidades, quando estão sujos, com fome ou cansados. Novamente, o choro representou o principal comportamento dos bebês que indica essa capacidade, sendo mencionado por oito dessas mães. Uma participante relatou que sua filha apresenta comportamentos mais ativos para fazer algo quando está com fome, suja ou cansada, como pode ser visto no exemplo: “(...) é assim, às vezes ela tá com sede, ai vê o copinho dela ali em cima. Ela mesma levanta, vai, sai daqui e sobe ali e pega o copo e bebe. (...) Ela, ela, pronto, quando ela tá suja, ela pega na fralda e mostra." (M20). Outra mãe, ainda nesse grupo, afirmou que o uso de vocalizações é o comportamento utilizado pelo bebê para comunicar seus estados.

Como parte da entrevista, foi perguntado: "Você acha que os bebês nascem com habilidades de comunicar suas necessidades?". Em resposta, 14 mães de bebês de quatro meses afirmaram que acham que os bebês nascem com essas habilidades. Quatro mães alegam que, no momento atual, ou seja, aos quatro meses, os bebês têm essas habilidades, no entanto, elas foram desenvolvidas ao longo do tempo, e os bebês não nasceram com elas. Já entre as mães de bebês nove meses, 11 mães responderam que eles nascem com a habilidade de comunicar suas necessidades. Cinco mães afirmaram que os bebês têm essas habilidades, no entanto, elas não estão presentes desde o nascimento, mas foram desenvolvidas com o tempo: "Se eles nascem já? Eu acho que não. Eles vão adquirindo com o passar do tempo, com os estímulos, né, com o passar do tempo." (M1).

Também foi solicitado que as mães descrevessem a capacidade dos seus bebês de terem suas necessidades atendidas; essa capacidade foi explorada em três domínios, quais sejam: necessidades cognitivas, necessidades socioemocionais e necessidades motoras. O primeiro domínio foi referente às necessidades cognitivas, $\mathrm{e}$ foi dado o seguinte exemplo às mães: "pegar objetos que ele acha interessantes". Entre as mães de bebês de quatro meses, dez afirmaram que seus filhos já conseguem pegar os objetos que eles acham interessantes. Dez mães relataram que seus bebês ainda não têm a habilidade de pegar desenvolvida, mas que eles têm preferências por determinados objetos e expressam isso por meio de outros comportamentos dotados de intenção, tais como o olhar. "Ela já, assim, ela não tem coordenação pra pegar, mas ela já, quando ela quer alguma coisa, ela fica olhando pro brinquedinho já." (M3).

No grupo de mães de bebês de 9 meses, as 20 participantes afirmaram que seus bebês têm preferências por alguns objetos que eles consideram mais interessantes e já são capazes de pegá-los. O exemplo a seguir ilustra as falas das mães ao fazerem referências às preferências dos bebês: "Então, hoje eu tava querendo que ela fosse pegar a boneca que ela ganhou de presente, mas ela não queria. Ela queria pegar o quadradozinho que é o encosto da porta. Então, ela queria ir lá, e por mais que eu botasse ela no meu caminho, ela voltava lá. E se de repente eu insisto, ela reclama, ela faz 'humhurrum'. Então, ela dá os sinais dela de que ela não quer aquilo, por mais que eи ou o pai ou alguém queira." 
(M12). Uma mãe apresentou outro tipo de comportamento, o apontar, que, além do pegar, demonstra a habilidade cognitiva e comunicativa do seu bebê em indicar seus objetos de interesse: "Ele já aponta" (M19).

Em seguida, foi solicitado às mães: "Descreva a capacidade do seu bebê de ter suas necessidades socioemocionais atendidas (por exemplo: ter certeza de que você está perto e atenta às comunicações sociais dele)". Todas as mães de bebês de quatro meses afirmaram que seus filhos têm essa capacidade. Além disso, a maioria das mães mencionou os comportamentos utilizados pelos bebês para se certificarem da presença delas. Dez mães citaram o choro como principal comportamento do bebê para ter suas necessidades socioemocionais atendidas. Três mães desse grupo mencionaram que seus bebês vocalizam na tentativa de chamar a atenção delas para suas necessidades. Três mães ressaltaram o comportamento dos seus bebês de olhar e prestar atenção na fala e nas ações da mãe.

Entre as mães de bebês de nove meses, todas também afirmaram que seus bebês têm a capacidade de solicitar que suas necessidades socioemocionais sejam atendidas. Seis mães relataram que seus bebês olham e prestam atenção nas falas e nas ações da mãe, esperando que esta satisfaça suas necessidades. Cinco mães mencionaram o choro como o principal comportamento do bebê para comunicar essas necessidades e fazer com que elas sejam atendidas. Cinco mães responderam que os bebês realizam movimentos específicos com o intuito de demonstrar suas necessidades socioemocionais, como no exemplo: "Quando ela me vê, ela balança logo as mãos. Ela tenta chamar minha atenção." (M4). Duas mães mencionaram o uso de vocalizações como comportamento utilizado para esse fim. Uma mãe fez referência ao sorriso.

Também foi solicitado às participantes: "Descreva a capacidade do seu bebê de ter suas necessidades motoras atendidas (por exemplo: ter certeza de que você o coloca no chão quando ele quer explorar algo)". Doze mães de bebês de quatro meses responderam que eles têm capacidade de ter suas necessidades motoras atendidas. Entre os comportamentos infantis referidos por essas mães o choro foi mencionado por quatro participantes. Quatro mães deste grupo também relataram que seus bebês demonstram esse tipo de necessidade através de movimentos corporais. No grupo de mães de bebês de nove meses, as 20 participantes afirmaram que seus bebês "pedem” para ir para o chão. Dentre essas 20 mães, 12 fazem referências a movimentos corporais como uma forma utilizada pelo bebê para demonstrar suas necessidades motoras: "Se ela tiver no braço e ela quiser ir pro chão, andar, ela se agonia. Tá no braço e se estica, quer se jogar." (M18).

A pergunta seguinte foi: "Quando seu bebê estende a mão para um brinquedo, lhe parece que ele pretende pegar o brinquedo?" As 20 mães de bebês de quatro meses responderam afirmativamente. Também no grupo de mães de bebês de nove meses, todas responderam afirmativamente a essa questão, como pode ser visualizado no exemplo: "Sim, eu acho que, quando ele vai, é pra pegar." (M17).

No que tange à pergunta "Quando seu bebê está olhando ao redor, você acha que isso é porque ele quer aprender algo?", das 20 mães de bebês de quatro meses, 15 percebem que, quando seus bebês olham ao redor, é porque eles querem aprender sobre o mundo. No grupo de mães de bebês de nove meses, 18 percebem que seus bebês querem aprender sobre o mundo quando eles estão olhando ao redor e destacam a capacidade dos seus bebês de mostrarem interesse por coisas novas: "Eu acho que sim, porque, às vezes, a gente tá sentado aqui, ele fica olhando assim pras coisas. Eu acho que ele tá observando, vendo o que aquilo é. Eu acho que ele tá aprendendo sim." (M1).

Quando perguntadas sobre "Você acredita que os bebês buscam experiências emocionais e têm maneiras de alcançar esse objetivo?", entre as mães de bebês de quatro meses, 15 responderam que percebem os bebês como capazes de buscar experiências emocionais e que, para alcançar esse objetivo, eles podem usar muitos comportamentos, tais como chorar, vocalizar, olhar, "fazer dengo" e movimentos corporais. Esse exemplo reflete a forma peculiar da comunicação infantil percebida pelas mães: "Acho que sim, só que diferente, né, de um adulto, do jeito deles, né." (M19). No tocante às mães de bebês de nove meses, 16 afirmaram que seus filhos buscam experiências emocionais e têm maneiras de alcançar esse objetivo, entre elas, chorar, "fazer dengo", vocalizar e movimentos corporais.

Sobre a pergunta "Você acha que os bebês sabem mais do que eles podem expressar?", dezoito mães de bebês de quatro meses afirmam que a capacidade de conhecimento dos bebês vai além das suas habilidades de expressão e que, ao longo do desenvolvimento, eles vão adquirindo novas habilidades que permitem a expressão comunicativa mais ampla. Dezessete mães de bebês de nove meses afirmam que os bebês sabem mais do que podem expressar.

No tocante à Percepção materna acerca da eficácia dos bebês nos outros, a seção foi composta por 10 questões. A primeira delas foi: "Você sente que o seu bebê está tentando lhe dizer algo?". No grupo de mães de bebês de quatro meses, todas as participantes afirmaram que sentem que seus bebês tentam lhes dizer algo. Alguns comportamentos infantis foram relatados pelas mães como tento um caráter comunicativo, tais como choro, vocalizações, sorriso e olhar. Entre as mães de bebês de nove meses, as 20 participantes também sentem que os seus bebês tentam se comunicar com elas. Os relatos maternos apresentaram comportamentos infantis que são considerados pelas mães como comunicativos, a saber, o olhar e vocalizações, conforme pode ser visto nos exemplos: "Ela derrubou a bolinha embaixo do móvel, aí ela ficava olhando pra mim, olhando pro pai e fazia 'Ahm, ahm'. Então, assim, querendo ou não, ela queria dizer: 'Ó, mamãe, caiu lá embaixo. Tira ali pra mim.", (M20).

A questão seguinte foi: “Quando seu bebê sorri, é porque ele quer que você faça algo para ele?". Entre as 20 mães de bebês de quatro meses, 14 responderam afirmativamente, sendo que sete dessas mães consideram que o sorriso tanto pode ser uma forma que o bebê utiliza para pedir que algo seja feito para ele, como também pode representar um agradecimento pelo que já foi feito ou apenas uma demonstração de felicidade. "Ah, eu acho que ele fica tentando chamar nossa atenção, né, pra brincar, pra, pra ir pro braço. Eu acredito que sim." (M13). No grupo de mães de bebês de nove meses, quatro acham que, quando seus bebês sorriem, é porque querem que elas façam algo por eles. 
Doze mães também acham que o sorriso pode representar um pedido do bebê, mas não apenas isso. Elas relatam que o sorriso pode ocorrer porque elas já atenderam alguma necessidade do bebê ou pode ser uma expressão de felicidade.

Também foi perguntado às participantes: "Quando seu bebê sorri, é porque ele sente que algo está lhe incomodando e ele pode fazer você se sentir melhor?" Entre as mães de bebês de quatro meses, 11 acreditam que sim, que o bebê pode sorrir para fazer com que elas se sintam melhor. Entre as mães de bebês de nove meses, sete responderam que percebem o bebê como sendo capaz de sorrir com a intenção de fazê-las sentirem-se melhor. Uma mãe afirmou que não sabia responder a essa questão.

Em seguida, as mães também foram questionadas: "Quando seu bebê sorri, você acha que ele pretende lhe dizer algo?" No grupo de mães de bebês de quatro meses, 18 consideram o sorriso como um comportamento comunicativo. "Com certeza. Alguma coisa ele tem a falar, né. Só que não sabe falar, tome riso pra cima." (M11). Entre as mães de bebês de nove meses, 19 acham que os bebês querem dizer alguma coisa por meio do sorriso.

Outra pergunta dessa seção foi "Quando seu bebê chora, você sente que ele sabe que você está perto e que pode cuidar das necessidades dele?". No grupo de mães de bebês de quatro meses, 19 mães afirmaram que sentem que, quando o bebê chora, é porque ele sabe que ela está perto e pode atender suas necessidades. Entre as mães de bebês de nove meses, todas responderam afirmativamente a essa questão, como ilustrado no exemplo: "Às vezes tem sim, às vezes ela chora justamente... eu sinto que ela chora pra isso. Quando eu me afasto, ela chora pra que eu volte." (M3).

Ainda remetendo à percepção materna acerca do choro do bebê, foi questionado: "Quando seu bebê chora, você sente que ele sabe que pode conseguir ajuda através do choro?". Todas as mães nos dois grupos de idade pesquisados afirmaram que o bebê sabe que pode conseguir ajuda por meio do choro.

Também foram apresentadas na entrevista três perguntas consideradas como itens negativos, a primeira delas foi: "O seu bebê sempre chora porque está com raiva de você?”, no grupo de mães de bebês de quatro meses, 17 responderam que não, por considerarem que o bebê ainda não pode sentir raiva. Três mães desse grupo consideram que, quando seus bebês não têm suas necessidades ou vontades satisfeitas, eles ficam com raiva e expressam isso por meio do choro. Entre as mães de bebês de nove meses, 15 acreditam que seus bebês ainda não sentem raiva. Cinco mães, em contrapartida, acham que seus bebês podem sentir raiva e choram para demonstrar esse sentimento. "Sempre. Quando ela se enraivece, ela chora. Não só de mim, como dos outros." (M3).

A segunda pergunta que explora comportamentos infantis tidos como negativos foi: "Quando seu bebê lhe machuca (ex.: mordendo enquanto está mamando ou chutando durante a troca de fraldas), você acha que ele faz de propósito?” Em relação às mães de bebês de quatro meses, 19 acham que, quando seus bebês as machucam, eles não têm intenção de fazê-lo. "De jeito nenhum. A gente sente a dor e tudo mais, mas não é de propósito de jeito nenhum." (M11). Todavia, uma mãe desse grupo considera que seu bebê, em alguns momentos, chega a machucá-la propositalmente. No grupo de mães de bebês de nove meses, 18 acham que seus filhos não as machucam de propósito. Duas outras mães, porém, acham que sim. "Ela não faz isso, porque se ela fizer eu vou repreender. Mas ela faz, porque, se eu deixasse, ela fazia de propósito." (M13).

O terceiro item negativo foi: "Você acha que alguns bebês são rancorosos?". Quinze mães de bebês de quatro meses responderam que acham que os bebês ainda não são capazes de sentir rancor. Cinco mães, por seu turno, acham que sim, que os bebês podem ser rancorosos. No grupo de mães de bebês de nove meses, 16 acham que os bebês não podem ser rancorosos. Quatro acham que eles podem, dependendo da maneira como são tratados, e que podem agir de forma a demonstrar esse sentimento: "Eu creio que sim, que tem assim, eu acho que tem hora que o bebê quer tanto aquela coisa, que fica aquela coisa. Ele insiste em querer descontar, assim, e bater. Bater na mãe, bater em qualquer pessoa ou então bater no chão." (M20).

Por fim, foi feita a seguinte pergunta às mães: "Você acha que seu filho tenta ajudá-la quando você está machucada?". No grupo de mães de bebês de quatro meses, seis mães acham que seus bebês tentam, de alguma forma, ajudá-las quando elas estão precisando, especialmente no que se refere ao aspecto emocional, tal como demonstrado nos exemplos a seguir: "De uma forma sim, de outra não. Não a de agir, mas a de passar pra gente a felicidade dele tá ao lado, aquela calma. Ele quer passar 'eu tô aqui!'. Não de chegar e cuidar do seu ferimento, não. Mas de passar harmonia pra gente, passa." (M11). No grupo de mães de bebês de nove meses, apenas duas mães percebem seus bebês como sendo capazes de ajudá-las quando elas estão machucadas. Uma mãe não soube responder a essa questão.

\section{Discussão}

O objetivo do presente estudo foi analisar as percepções maternas acerca da comunicação intencional infantil pelo importante impacto delas nas interações mãe-bebê. Isto porque, o modo como as mães veem essa habilidade infantil reflete nas interações iniciais, guia as práticas das mães com o bebê e influencia o desenvolvimento sociocomunicativo e cognitivo infantil (Burchinal et al., 2010; Feldman \& Reznick, 1996). Os estudos na área referem que as mães que percebem seus filhos como capazes de realizar comportamentos com uma intenção definida tendem a estimular tais ações e responder de acordo com as configurações específicas do contexto.

A análise das respostas das participantes às questões referentes às seções "percepção materna acerca da autoeficácia dos bebês" e "eficácia dos bebês nos outros" permitiu identificar os principais comportamentos comunicativos intencionais infantis, de acordo com a visão das participantes. Esses resultados são apresentados de modo sintético na Tabela 1 e discutidos detalhadamente em seguida.

A Tabela 1 exibe dados sobre a compreensão das mães acerca dos aspectos comunicativos do desenvolvimento infantil. Diante disso, foi possível identificar variações dessas percepções considerando-se a idade do bebê e as habilidades específicas de cada período do desenvolvimento. Verificou-se 
Tabela 1. Síntese dos resultados encontrados em cada seção

\begin{tabular}{|c|c|c|}
\hline Seções & 4 meses & 9 meses \\
\hline 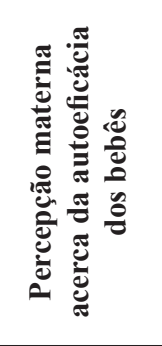 & $\begin{array}{l}\text { - A maioria das mães percebe o choro como um } \\
\text { comportamento utilizado pelo bebê para comunicar } \\
\text { suas necessidades. } \\
\text { Prevalência do choro como principal comportamento } \\
\text { comunicativo mencionado pelas mães. } \\
\text { - Referências às vocalizações, olhar, movimentos } \\
\text { corporais e "fazer dengo" como outros } \\
\text { comportamentos comunicativos usados pelo bebê a } \\
\text { fim de satisfazer suas necessidades. }\end{array}$ & $\begin{array}{l}\text { - A maioria das mães percebe o choro como um } \\
\text { comportamento utilizado pelo bebê para comunicar } \\
\text { suas necessidades intencionalmente. } \\
\text { Referência frequente a movimentos corporais } \\
\text { utilizados pelo bebê como comportamento } \\
\text { comunicativo intencional. } \\
\text { - Relato materno sobre o uso do apontar intencional. } \\
\text { - Relato materno sobre o olhar alternado } \\
\text { (intencionalmente comunicativo). }\end{array}$ \\
\hline 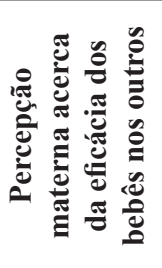 & $\begin{array}{l}\text { - Predomínio do choro como principal comportamento } \\
\text { utilizado pelo bebê para afetar o outro. } \\
\text { Choro percebido como um comportamento eficaz } \\
\text { para conseguir ajuda. } \\
\text { - Sorriso percebido pelas mães como um importante } \\
\text { comportamento usado pelo bebê para que suas } \\
\text { necessidades sejam atendidas. }\end{array}$ & $\begin{array}{l}\text { - Choro percebido como um comportamento eficaz } \\
\text { para conseguir ajuda (intencional). } \\
\text { - Sorriso percebido pelas mães como um importante } \\
\text { comportamento usado pelo bebê para que suas } \\
\text { necessidades sejam atendidas (intencional). } \\
\text { - Cinco mães percebem que seus bebês choram por } \\
\text { estar com raiva. }\end{array}$ \\
\hline
\end{tabular}

que a maioria das mães, tanto dos bebês de quatro meses, quanto dos bebês de nove meses, percebe seus filhos como tendo habilidades comunicativas intencionais. Todavia, os exemplos referidos pelas participantes apresentam diferenças importantes entre os dois grupos. O choro e o sorriso foram mencionados principalmente pelas mães de bebês de quatro meses, enquanto que as mães de bebês de nove meses, além desses comportamentos, destacaram as vocalizações, o olhar, a alternância do olhar e o apontar.

$\mathrm{O}$ fato de o choro ter sido o comportamento mais referido pelas mães de bebês de quatro meses, enquanto que, entre as mães de bebês de nove meses, as vocalizações estiveram mais presentes, pode ser justificado pelo período e situação social do desenvolvimento dos bebês nos diferentes períodos estudados. Como demonstram estudos acerca do desenvolvimento infantil (Brazelton, 1994; Rochat, 2009; Seidl-de-Moura et al., 2004; Stephen, Dunlop, \& Trevarthen, 2003; Striano \& Rochat, 1999; Trevarthen, 2011), um dos principais comportamentos comunicativos do bebê, desde o nascimento, é o choro. Todavia, o processo de reequipamento da criança permite que novas habilidades sejam construídas e aprimoradas, possibilitando que os bebês utilizem comportamentos mais sofisticados e intencionais (Vygotsky \& Luria, 1996).

Sobre esse aspecto, resultados expressos pelas falas maternas encontram respaldo em um estudo realizado por Braz Aquino e Salomão (2011c), com mães de bebês de 6, 9 e 12 meses. No tocante às percepções maternas acerca das habilidades dos bebês de chamarem a atenção das mães, as autoras verificaram que o choro, apesar de ter sido mencionado por mães dos três grupos, apresentou maior frequência de evocações entre as mães dos bebês mais novos. Por outro lado, comportamentos como o gesto de puxar a mãe e vocalizar "mamã" foram referidos apenas por mães cujos bebês já estavam no último trimestre do primeiro ano de vida.

Os relatos das mães, apresentados também no presente estudo, permitem supor que as habilidades sociocomunicativas dos bebês aos nove meses são mais aprimoradas e direcionadas para um objetivo determinado. Nesse sentido, por volta dos 9 meses, o choro deixa de ser o principal meio utilizado pelo bebê para comunicar suas necessidades e chamar a atenção materna. $\mathrm{O}$ caráter intencional que fundamenta os comportamentos infantis a partir desse período possibilita que a criança aumente seu efeito no meio social e tenha suas necessidades atendidas (Grosse, et al., 2010; Tomasello, 1999, 2003; Tomasello \& Carpenter, 2007).

No que tange ao sorriso, entende-se, em consonância com a literatura e com os relatos maternos, que ele proporciona maior engajamento em interações face a face, envolvendo trocas afetivas e comunicativas (Goldstein, Schwade, \& Bornstein, 2009; Mendes, Seidl-de-Moura, \& Siqueira, 2009; Rochat, 2007, 2009). Dados empíricos apresentados por Striano e Stahl (2005) sugerem que bebês de 3, 6 e 9 meses variaram seus olhares e sorrisos dependendo da atenção visual coordenada pelo parceiro social e do afeto deste.

No tocante às vocalizações, elas se tornam, paulatinamente, mais elaboradas, semelhantes às palavras da língua formal, e acompanham o uso convencional de gestos enquanto comportamentos sociais (Goldin-Meadow, 2009). Em seu modo mais sofisticado, as vocalizações podem assumir formas ritualizadas, que são indicadores relevantes da comunicação intencional, antes do surgimento da fala propriamente dita (Laakso et al., 1999; Volterra, Caselli, Capirci, \& Pizzuto, 2004). Essas vocalizações permitem que o bebê atue e se comunique de modo mais eficiente no meio social, influenciando seu desenvolvimento comunicativo, afetivo e sociocognitivo mais amplo (Mendes \& Pessôa, 2013; Vygotsky, 1996).

A respeito do olhar, os exemplos das mães deste estudo apresentam configurações diferentes quando considerada a idade do bebê. Sobre isso, Feldman e Reznick (1996) ressaltam que o olhar direcionado para o adulto por meio da referência compartilhada pode ser considerado um ato intencional. Resultados de estudos realizados por Braz Aquino e Salomão (2011a) mostraram que bebês no último trimestre do primeiro ano de vida apresentaram habilidades de comunicação intencional, sendo o olhar alternado uma delas. 
Cabe ressaltar que apenas no grupo de mães de bebês de nove meses foi mencionado o gesto de apontar, o que sugere, de acordo com os relatos, que os bebês aos nove meses usam mais recursos comunicativos intencionais que aos quatro meses. Lima-Silva et al. (2010) também verificaram que mães de bebês de 9 e 12 meses, relataram que seus filhos usam o gesto de apontar para se comunicar; esse comportamento foi mais presente nos relatos das mães dos bebês de 12 meses, sugerindo um aumento da frequência desse gesto a partir dos nove meses de vida, o que corrobora o estudo de Volterra et al. (2004).

Ainda sobre o gesto de apontar, autores (Goldin-Meadow, 2009; Iverson, Capirci, Volterra, \& Goldin-Meadow, 2008; Nogueira, 2009; Tomasello, 1999, 2003; Volterra et al., 2004; Vygotsky, 2007) esclarecem que ele é um preditor da capacidade linguística, por promover o crescimento do aprendizado de palavras, auxiliado pelos rótulos utilizados pelos pais dos objetos para onde o bebê aponta. Assim, os bebês que já usam o gesto de apontar podem, por meio das interações, estar expostos a novas condições para seu próprio desenvolvimento vocabular.

Nessa trajetória de desenvolvimento, as novas aquisições comunicativas do bebê, associadas ao desenvolvimento motor no último trimestre do primeiro ano de vida potencializam o comportamento exploratório e interativo. De modo interrelacionado, as novas aquisições e experiências motoras infantis, por seu turno, são básicas para o desenvolvimento de habilidades mentais e sociais do bebê (Lopes et al., 2009).

Segundo os relatos maternos, os bebês ainda não são capazes de expressar sentimentos ou ações negativas, como sentir raiva, rancor e machucar a mãe intencionalmente. De forma geral, as mães parecem conceber que seus bebês ainda não têm consciência do que é certo ou errado e, quando o fazem, é de modo involuntário. Entretanto, houve relatos isolados de mães que acreditam que seus bebês, mesmo com poucos meses de idade, já são capazes de tais sentimentos ou ações, resultados também encontrados por Burchinal et al. (2010) ao investigarem a relação entre estilos parentais e práticas de punição física em bebês.

Sobre esse aspecto, autores (Burchinal et al., 2010; Feldman \& Reznick, 1996; Reznick, 1999) sugerem que as percepções maternas acerca da intencionalidade comunicativa infantil podem estar ligadas às crenças sobre disciplina, segundo as quais, desde cedo, faz-se necessário ensinar os bebês a respeitarem as regras e a autoridade para que eles não se comportem de forma negativa para machucar ou "testar" os outros. Esse tipo de percepção materna também está relacionado com a influência dos valores e da cultura, que são refletidos nos comportamentos parentais.

Espera-se que a discussão e os dados empíricos apresentados neste estudo, a partir da entrevista proposta, possam favorecer uma maior compreensão sobre as habilidades sociocomunicativas dos bebês e o papel das atribuições e percepções maternas nas interações e no desenvolvimento infantil, fornecendo subsídios que auxiliem profissionais a levantar indicadores de possíveis alterações na linguagem e na comunicação, pela via dos relatos maternos.

Menciona-se, ainda, que os resultados apresentados devem ser analisados com cautela, já que o número de participantes e as características próprias de cada contexto de desenvolvimento não permitem generalizações. Por essa razão, eles devem ser analisados considerando-se as peculiaridades de cada cenário sociocultural nos quais as mães estão inseridas, as especificidades de cada bebê e as características próprias de cada mãe.

Sugere-se que futuros estudos investiguem essa temática de modo longitudinal, o que permite uma compreensão das percepções maternas e do desenvolvimento sociocomunicativo de cada bebê de forma contínua. Estudos que analisem também as interações mãe-bebê, por meio de uma análise microgenética e videográfica, em conjunto com as percepções maternas, podem fornecer dados mais precisos sobre o impacto da visão da mãe acerca da habilidade de comunicação intencional de bebês nas trocas interativas. Além disso, indica-se que amostras de futuras pesquisas incluam maior número de mães usuárias dos serviços públicos de saúde e profissionais do campo da educação infantil.

\section{Referências}

Bardin, L. (2002). Análise de conteúdo (A. Neto, \& A. Pinheiro. Trads.). São Paulo: Livraria Martins Fontes. (Trabalho original publicado em 1977).

Bloom, L. (2000). Intentionality and theories of intentionality in development: Essay review of developing theories of intention. Human Development, 43, 178-185. doi: 10.1159/000022674.

Bornstein, M. H. (2013). Mother - Infant Attunement: A Multilevel Approach via Body, Brain, and Behavior. In M. Legerstee, D. Haley, \& M. H. Bornstein (Eds.), The Infant Mind: Origins of the Social Brain. (pp. 266-289). New York, NY: Guilford Press.

Braz Aquino, F. S., \& Salomão, N. M. R. (2010). Intencionalidade Comunicativa: teorias e implicações para a cognição social infantil. Estudos de Psicologia (Campinas), 27(3), 413-420.

Braz Aquino, F. S., \& Salomão, N. M. R. (2011a). Habilidades sociocomunicativas de bebês no primeiro ano de vida: um estudo longitudinal. Paidéia, 21(50), 335-344.

Braz Aquino, F. S., \& Salomão, N. M. R. (2011b). Intencionalidade Comunicativa e Atenção Conjunta: Uma análise em Contextos Interativos Mãe-bebê. Psicologia: Reflexão e Crítica, 24(1), 107-115.

Braz Aquino, F. S., \& Salomão, N. M. R. (2011c). Percepções maternas acerca das habilidades sociocomunicativas de bebês. Psicologia: Ciência e Profissão, 31(2), 252-267.

Brazelton, T. B. (1994). Momentos decisivos do desenvolvimento infantil. São Paulo, SP: Martins Fontes.

Burchinal, M., Skinner, D., \& Reznick, J. S. (2010). European American and African American mothers' beliefs about parenting and disciplining infants: a mixed-method analysis. Parenting: Science And Practice, 10, 79-96.

D'Entremont, B., \& Seamens, E. (2007). Do infants need social cognition to act socially? An alternative look at infant pointing. Child Development, 78(3), 723-728.

Feldman, R., \& Reznick, J. S. (1996). Maternal perception of infant intentionality at 4 and 8 months. Infant Behavioral Development, 19, 483-496.

Franco, M. L. P. B. (2008). Análise de Conteúdo. Brasília, DF: Liber Livro Editora. 
Gallese, V., \& Rochat, M. (2013). The Evolution of Motor Cognition: Its Role in the Development of Social Cognition and Implications for Autism Spectrum Disorder. In M. Legerstee, D. Haley, \& M. H. Bornstein (Eds.), The Infant Mind: Origins of the Social Brain. (pp. 19-47). New York, NY: Guilford Press.

Goldin-Meadow, S. (2009). How gesture promotes learning throughout childhood. Child Development Perspectives, 3(2), 106-111.

Goldstein, M. H., Schwade, J. A., \& Bornstein, M. H. (2009). The value of vocalizing: five-month-old infants associate their own noncry vocalizations with responses from caregivers. Child Development, 80 (3), 636-644

Gratier, M., \& Trevarthen, C. (2007). Voice, vitalty and meaning: on the shaping of the infant's utterances in willing engagement with culture. Comment os Bertaus's "on the notion of voice". International Journal for Dialogical, 2(1), 169-181.

Grosse, G., Behne, T., Carpenter, M., \& Tomasello, M. (2010). Infants communicate in order to be understood. Developmental Psychology, 46(6), 1710-1722

Harkness, S., \& Super, C. M. (1996). Parents' cultural belief systems: their origins, expressions, and consequences. New York, NY: Guilfor Press.

Harkness, S., \& Super, C, M. (2006) Themes and variations: Parental Ethnotheories in Western Cultures. In K. H. Rubin, O. B. Chung, (Eds.), Parental beliefs, behavior, and parent-child relations: a cross-cultural perspective. (pp.61-80). New York, NY: Editora Routledge.

Iverson, J. M., Capirci, O., Volterra, V., \& Goldin-Meadow, S. (2008). Learning to talk in a gesture-rich world: early communication in Italian vs. American children. First Language, 28(2), 164-181.

Laakso, M.-L., Poikkeus, A.-M., Katajamäk, J., \& Lyytinen, P. (1999). Early intentional communication as a predictor of language development in young toddlers. First Language, 19, 207-231.

Legerstee, M. (2013). The Developing Social Brain: Social Connections and Social Bonds, Social Loss, and Jealousy in Infancy. In M. Legerstee, D. Haley, \& M. H. Bornstein, (Eds.), The Infant Mind: Origins of the Social Brain. (pp. 223-247). New York, NY: Guilford Press.

Legerstee, M., \& Markova, G. (2007). Intentions make a difference: Infant responses to still-face and modified still-face conditions. Infant Behavior and Development, 30, 232-250.

Lima-Silva, F. L., Santos, R. C. S., Andrade, T. F., Souza, A. G., Barreto, I. O., Coelho, R. S., . . . Braz Aquino, F. S. (2010). Levantamento das concepções maternas acerca das capacidades sociocomunicativas de bebês no primeiro ano de vida: um estudo na cidade de Campina Grande-PB. In Anais da XL Reunião Anual da Sociedade Brasileira de Psicologia. Curitiba, PR.

Lopes, R. C. S., Vivian, A. G., Oliveira, D. S., Silva, C., Piccinini, C. A., \& Tudge, J. (2009). "Quando eles crescem, eles voam”: percepções e sentimentos maternos frente ao desenvolvimento infantil aos 18 - 20 meses. Psicologia em Estudo, 14(2), 221232.

Markova, G., \& Legerstee, M. (2008). How infants come to learn about the minds of others. Zero to Three, 28(5), 26-31.

Mendes, D. M. L. F., \& Seidl-de-Moura, M. L. (2009). Expressões faciais de emoção em bebês: importância e evidências. Estudos de Psicologia, 9, 307-327.
Mendes, D. M. L. F., Seidl-de-Moura, M. L., \& Siqueira, J. O. (2009). The ontogenesis of smiling and its association with mothers' affective behaviors: a longitudinal study. Infant Behavior \& Development, 32, 445-453.

Mendes, D. M. L. F., \& Pessôa, L. F. (2013b). Emotion, affection and maternal speech in parental care. In M. L. Seidl-de-Moura (Ed.), Parenting in South American and African Contexts. (pp. 130-145). InTech. http://creativecommons.org/licenses/by/3.0.

Nogueira, S. E., \& Seild de Moura, M. L. (2007). Intersubjetividade: perspectivas teóricas e implicações para o desenvolvimento infantil inicial. Revista Brasileira de Desenvolvimento Humano, 17(2), 128-138.

Olson, D. R., Astington, J. W., \& Zelazo, P. D. (1999). Actions, intentions and attribuitions. In P. D. Zelazo, J. W. Astington, \& D. R. Olson (Eds.), Developing theories of intention: social undertanding and self-control (pp. 1-13). Mahwah, NJ: Lawrence Erlbaum Associates.

Pasquali, L. (2010). Testes referentes a construto: teoria e modelo de construção. In L. Pasquali (Ed.). Instrumentação Psicológica: fundamentos e práticas (pp. 165-198). Porto Alegre, RS: Artmed.

Reznick, J. S. (1999). Influences on maternal attribuition of infant intentionality. In P. D. Zelazo, J. W. Astington, \& D. R. Olson (Eds.), Developing theories of intention: social understanding and self-control (pp. 243-267). Mahwah, NJ: Lawrencw Erlbaum Associates.

Reznick, J. S., \& Schwartz, B. B. (2001) When is an assessment an intervencion? Parent Perception of Infant Intentionality and Language. Journal of the American Academy of Child and Adolescent Psychiatry, 40(1), 11-17.

Rivero, M. (2003). Los inícios de la comunicación: La intencionalidad comunicativa y el significado como procesos graduales. Anuário de Psicologia, 34(3), 337-356.

Rivero, M. (2010). Maternal expression of communicative intentions and pragmatic fine tuning in early infancy. Infant Behavior and Development, 33, 373-386.

Rochat, P. (2007). Intentional action arises from early reciprocal exchanges. Acta Psychologica, 124, 8-25.

Rochat, P. (2009). Others in Mind: social origins of selfconsciousness. New York, NY: Cambrige Univerty Press.

Sanchez, S. E. (1991). Observacion de la comunicacion intencional preverbal: um sistema de codificacion basado en el concepto de categoria natural. Psicothema, 3(2), 359-380.

Seidl-de-Moura, M. L., Mendes, D. M. L. F., Vieira, M. L., Kobarg, A. L., Pessôa, L. F., \& Bandeira, T. T. A. (2013). Brazilian Mothers' Description of their Children: Dimensions of Autonomy and Relatedness. Psicologia: Teoria e Pesquisa, 29(3), 249-255

Seidl-de-Moura, M. L., Ribas, A. F. P., Seabra, K. C., Pessôa, L. F., Ribas Jr., R. C., \& Nogueira, S. E. (2004). Interações iniciais mãe-bebê. Psicologia: Reflexão e Crítica, 17(3), 295-302.

Stephen, C., Dunlop, A.-W., \& Trevarthen, C. (2003). Meeting the needs of children from bith to three: research evidence and implications for out-of-hom provision. Scottish Executive Education Department. Insight, 6, 1-13.

Striano, T., \& Reid, V. M. (2006) Social cognition in the first year. Trends in Cognitive Sciences, 10(10), 471-476.

Striano, T., \& Rochat, P. (1999). Developmental link between dyadic and triadic social competence in infancy. British Journal of Developmental Psychology, 17, 551-562. 
Striano, T., \& Stahl, D. (2005). Sensitivity to triadic attention in early infancy. Developmental Science, 8(4), 333-343.

Tomasello, M. (1999). Having intentions, understanding intentions, and understanding communicative intentions. In P. D. Zelazo, J. W. Astington, \& D. R. Olson (Eds.), Developing theories of intention: social understanding and self-control (pp. 63-76). Mahwah, NJ: Lawrencw Erlbaum Associates.

Tomasello, M. (2003). Origens Culturais da aquisição do conhecimento humano: Tópicos (C. Berliner, Trad.). São Paulo, SP: Martins Fontes.

Tomasello, M., \& Carpenter, M. (2007). Shared Intencionality. Development Science, 10(1), 121-125.

Trevarthen, C. (1979). Communication and cooperation in early infancy: a description of primary intersubjectivity. In M. Bullowa (Ed.), Before speech: the beginning of interpersonal communication (pp. 321-347). London: Cambridge University Press.
Trevarthen, C. (2011). What is it like to be a person who knows nothing? Defining the active intersubjective mind of a newborn human being infant and child development. Infant and Child Development, 20, 119-135.

Volterra, V., Caselli, M. C., Capirci, O., \& Pizzuto, E. (2004). Gesture and the emergence and development of language. In M. Tomasello, \& D. Slobin, (Eds.), Elizabeth Bates: A Festschrift. (pp. 3-40). Mahwah, NJ: Lawrence Erlbaum Associates.

Vygotsky, L. S. (1996). El primer año (L. Kuper, Trad.). Obras Escogidas: Psicología infantil. Tomo IV (pp. 275-318). Madrid: Visor. (Trabalho original publicado em 1932)

Vygotsky, L. S. (2007). A Formação social da mente: O desenvolvimento dos processos psicológicos superiores. São Paulo, SP: Editora Martins Fontes. (Trabalho original publicado em 1984)

Vygotsky, L. S., \& Luria, A. R. (1996). Estudos sobre a história do comportamento: simios, homem primitivo e criança. Porto Alegre, RS: Artes Médicas. 